\title{
EFECTO DE LA SUPLEMENTACIÓN DE ÁCIDOS ORGÁNICOS SOBRE LOS PARÁMETROS PRODUCTIVOS EN POLLOS DE ENGORDE
}

\author{
Effect of the Supplementation of Organic Acids on Productive Parameters \\ IN BROILERS
}

Sergio Gonzáles A. ${ }^{1}$, Eliana Icochea D. ${ }^{1,4}$, Pablo Reyna S. ${ }^{1}$, John Guzmán G. ${ }^{1}$, Fernando Cazorla M. ${ }^{3}$, Julia Lúcar ${ }^{3}$, Fernando Carcelén C. ${ }^{2}$, Viviana San Martín ${ }^{1}$

\section{Resumen}

Se evaluó el efecto de la suplementación de una mezcla de ácidos orgánicos y sus sales sobre los parámetros productivos en pollos de engorde. Se utilizaron 333 pollos machos de un día de edad de la línea Cobb-Vantress 500, divididos en tres tratamientos con tres repeticiones por tratamiento: T1, dieta con antibiótico Zinc Bacitracina; T2, dieta con ácidos orgánicos, y T3, tratamiento control, dieta sin promotor de crecimiento. A los 42 días de edad, la conversión alimenticia de T2 fue 5.2\% menor que T3 ( $<<0.05)$; sin embargo, no se observaron diferencias estadísticas entre tratamientos por efecto del peso corporal, ganancia de peso, consumo de alimento, porcentaje de mortalidad e índice de eficiencia productiva. Los resultados permiten concluir que los ácidos orgánicos pueden remplazar eficientemente a los promotores de crecimiento tipo antibióticos en la alimentación de las aves.

Palabras clave: ácidos orgánicos, zinc bacitracina, parámetros productivos, pollos de engorde

\section{Abstract}

The objective of the study was to evaluate the effect of a mixture of organic acids and their salts on the productive parameters in broilers. A total of 133 1-day-old male chicks of the Cobb Vantress 500 Line were distributed in three treatments with three repetitions per treatment: T1, diet with Zinc-Bacitracin; T2, diet containing organic acids; and T3, control treatment, diet without growth promoter. At 42 days of age, feed conversion in T2 was 5.2\% less than in T3 ( $\mathrm{p}<0.05$ ); however, no statistical differences were observed between treatments regarding body weight, body weight gain, feed consumption, mortality

\footnotetext{
${ }^{1}$ Laboratorio de Patología Aviar, ${ }^{2}$ Laboratorio de Bioquímica, Nutrición y Alimentación Animal, Facultad de Medicina Veterinaria, Universidad Nacional Mayor de San Marcos, Lima

${ }^{3}$ Línea de Nutrición, Inversiones Veterinarias S.A., Lima

${ }^{4}$ E-mail: eliana.icochea@gmail.com
} 
rate and productive efficiency index. The results showed that organic acids can efficiently replace the use of antibiotics as growth promoters in the diets of broilers.

Key words: organic acids, zinc bacitracin, productive parameters, broiler chickens

\section{INTRODUCCIÓN}

En el Perú, la avicultura es una de las actividades económicas más importantes, genera el $2.5 \%$ del PBI nacional y constituye el $70 \%$ de proteína de origen animal consumida por la población. La actividad avícola ha experimentado un explosivo crecimiento y desarrollo en las últimas décadas, como consecuencia del avance tecnológico en busca de mejorar la productividad (APA, 2011; MINAG, 2011).

Dentro de las medidas tomadas, se encuentra la incorporación de antibióticos promotores de crecimiento (APC) en el alimento con el fin de mejorar la productividad y disminuir la incidencia de enfermedades. Sin embargo, los APC han pasado a ser motivo de polémica en todo el mundo, debido a la posibilidad del desarrollo de resistencias microbianas que pueden ser transmitidas al hombre; lo cual ha conllevado a la prohibición del uso de estas sustancias como promotoras de crecimiento en la alimentación animal en muchos países (Peris y Pérez, 2001). Debido a esto, existe un marcado interés en utilizar alternativas naturales a los APC, tales como enzimas, prebióticos, probióticos, extractos de plantas y acidificantes, los cuales pueden limitar el número de bacterias patógenas, mejorar la capacidad de absorción del intestino y mejorar el rendimiento productivo (López et al., 2009).

Entre los acidificantes se encuentran los ácidos orgánicos, los cuales son sustancias que poseen al menos un grupo carboxilo $(-\mathrm{COOH})$ en su molécula (Penz, 1991). Estos ácidos pueden considerarse sustancias se- guras, ya que no abandonan el tracto digestivo y por ello no dejan residuos en los productos animales (Carro y Ranilla, 2002).

La eficacia de inhibición microbiana de un ácido orgánico depende principalmente del valor de su pKa, que es el pH al cual un 50\% del ácido está disociado, teniendo la mayoría valores entre 3 y 5 . Los ácidos orgánicos de cadena corta con pKa elevado tendrían una acción antimicrobiana más efectiva, ya que permitiría que una mayor cantidad de ácido se encuentre en forma no disociada (Dibner y Buttin, 2002).

La acción de los ácidos orgánicos sobre la microflora intestinal se lleva a cabo mediante dos mecanismos: (a) reduciendo el $\mathrm{pH}$ del alimento y del tracto digestivo, creando un entorno negativo para el crecimiento de microorganismos patógenos de los géneros Escherichia, Clostridium y Salmonella; y (b) el efecto antimicrobiano específico debido a la forma no disociada, alterando varios procesos esenciales para la vida de los microorganismos, principalmente Gram negativos (Peris y Pérez, 2001; Dinabandhu et al., 2009). Los ácidos atraviesan la membrana lipídica de la célula bacteriana, quedando expuesto al $\mathrm{pH}$ neutro interno de la bacteria, donde se disocia liberando protones $(\mathrm{H}+)$ y aniones (A-) (Van Immerseel et al., 2009).

Los protones $\mathrm{(H+}$ ) disminuyen el $\mathrm{pH}$ interno y, debido a que las bacterias sensibles al $\mathrm{pH}$ no toleran una diferencia muy grande entre el pH interno y el externo, se activa un mecanismo específico (bomba de $\mathrm{H}+$ ATPasa) que permite que el $\mathrm{pH}$ interno retorne a su nivel normal. Este fenómeno consume energía y, eventualmente, puede detener el crecimiento de la bacteria e incluso 
matarla. Además, muchas enzimas esenciales para el metabolismo microbiano se inactivan con $\mathrm{pH}$ ácido (Gauthier, 2002). La parte aniónica (A-) del ácido queda atrapada dentro de la bacteria, porque sólo en su forma no disociada se difunde libremente a través de la pared celular. La acumulación de aniones (A-) se torna tóxica para la bacteria, lo que conduce a problemas osmóticos internos para la bacteria (Gauthier, 2002).

Además, la acidificación tiene el potencial de controlar a las bacterias entéricas, tanto patógenas como no patógenas. Ácidos orgánicos, como fórmico, fumárico, propiónico y sórbico han sido utilizados en el concentrado de pollos de engorde, provocando una respuesta positiva. Incluso, se reporta que el ácido fórmico y propiónico en la dieta de los pollos reducen la incidencia de Salmonella en la canal, lo cual es importante para la salud pública (Alp et al., 1999; Al-Kassi y Mohssen, 2009).

El presente estudio tuvo como objetivo evaluar la inclusión de ácidos orgánicos en el alimento sobre los parámetros productivos en pollos de engorde.

\section{Materiales y MéTodos}

\section{Lugar de Estudio y Animales}

El estudio se llevó a cabo en el galpón experimental del Laboratorio de Producción Avícola y las necropsias en el Laboratorio de Patología Aviar de la Facultad de Medicina Veterinaria, Universidad Nacional Mayor de San Marcos, Lima. La fase experimental se desarrolló entre junio y julio de 2010.

Se utilizaron 333 pollos de engorde, machos de un día de edad, de la línea CobbVantress 500. El alimento para el engorde fue de tipo comercial y se administró ad libitum según la fase de producción: Pre-inicio (1-10 días), Inicio (11-22 días), Crecimiento (23-34 días), Acabado (35-39 días) y Finalizador (40-42 días).
En planta de incubación, las aves fueron vacunadas al primer día de edad contra la Enfermedad de Marek y Gumboro, Bronquitis Infecciosa (H120) y Enfermedad de Newcastle, y en el galpón experimental, a los 8 días de edad contra la enfermedad de Gumboro (cepa S706), a los 13 días contra la Enfermedad de Newcastle y a los 18 días contra la enfermedad de Gumboro (cepa 2512).

\section{Diseño Experimental}

Las aves fueron divididas en forma completamente aleatoria en tres tratamientos con tres repeticiones de 37 aves cada uno. Los tratamientos fueron:

T1: Control positivo. Con el antibiótico Zinc Bacitracina en el alimento, en dosis de $500 \mathrm{~g} / \mathrm{t}$ en el alimento de pre-inicio e inicio, y de $300 \mathrm{~g} / \mathrm{t}$ en el de crecimiento y acabado.

T2: Con el producto acidificante, una mezcla de ácidos orgánicos y sus sales (ácido fórmico, ácido propiónico, formiato de amonio, propionato de amonio y un excipiente), en dosis de $2 \mathrm{~kg} / \mathrm{t}$ desde el principio hasta el término de acabado (39 días).

T3: Control negativo, sin aditivo promotor de crecimiento en el alimento.

\section{Manejo de las Aves}

Las aves fueron criadas a galpón abierto, en un mismo ambiente sobre piso de cemento, con cama de viruta de madera, en una densidad de 10 aves por metro cuadrado. Las condiciones ambientales durante el experimento se manejaron de acuerdo a la edad de las aves, utilizando cortinas externas para controlar la temperatura ambiental, en especial en las horas de mayor calor del día, además de un «cielo raso» como microclima, para facilitar un ambiente de confort a las aves. Los corrales fueron divididos con mallas metálicas. 
Cuadro 1. Parámetros productivos en pollos de engorde de la línea Cobb-Vantress 500 a los 42 días de edad, en respuesta a la suplementación con ácidos orgánicos y antibiótico ${ }^{1}$

\begin{tabular}{ccccccc}
\hline & $\begin{array}{c}\text { Peso } \\
\text { corporal }\end{array}$ & $\begin{array}{c}\text { Ganancia } \\
\text { de peso }\end{array}$ & $\begin{array}{c}\text { Consumo } \\
\text { de } \\
\text { alimento }\end{array}$ & ICA $^{2}$ & Viabilidad & IEPE $^{3}$ \\
\hline T1 & 2893 & 2849 & 5150 & $1.780^{\mathrm{a}}$ & 94.6 & $366.1^{\mathrm{a}}$ \\
$\mathrm{T} 2$ & 2926 & 2880 & 5073 & $1.734^{\mathrm{a}}$ & 90.1 & $361.9^{\mathrm{a}}$ \\
$\mathrm{T} 3$ & 2879 & 2835 & 5254 & $1.825^{\mathrm{b}}$ & 94.6 & $355.2^{\mathrm{a}}$ \\
\hline
\end{tabular}

${ }^{a, b}$ Superíndices diferentes dentro de columnas indican diferencia estadística $(p<0.05)$

1 T1: Suplementados con antibiótico; T2; Suplementados con ácidos orgánicos; T3: Grupo control no suplementado

2 Índice de Conversión Alimenticia

3 Índice de Eficiencia Productivo Europeo

Cuadro 2. Causas de mortalidad a los 42 días de edad en pollos de engorde de la línea CobbVantress 500 sometidos a suplementación con ácidos orgánicos y antibiótico ${ }^{1}$

\begin{tabular}{|c|c|c|c|c|c|c|c|c|c|c|}
\hline & \multicolumn{2}{|c|}{ Colibacilosis } & \multicolumn{2}{|c|}{ Muerte súbita } & \multicolumn{2}{|c|}{ Ascitis } & \multicolumn{2}{|c|}{$\mathrm{CCPT}^{2}$} & \multicolumn{2}{|c|}{ Total } \\
\hline & $\mathrm{N}$ & $\%$ & $\mathrm{~N}$ & $\%$ & $\mathrm{~N}$ & $\%$ & $\mathrm{~N}$ & $\%$ & $\mathrm{~N}$ & $\%$ \\
\hline $\mathrm{T} 1$ & 0 & 0.0 & 1 & 0.9 & 3 & 2.7 & 2 & 1.8 & 6 & 5.4 \\
\hline $\mathrm{T} 2$ & 1 & 0.9 & 0 & 0.0 & 2 & 1.8 & 8 & 7.2 & 11 & 9.9 \\
\hline $\mathrm{T} 3$ & 0 & 0.0 & 1 & 0.9 & 2 & 1.8 & 3 & 2.7 & 6 & 5.4 \\
\hline
\end{tabular}

\section{Parámetros en Evaluación}

- Peso corporal promedio y ganancia de peso: Todas las aves se pesaron al primer día de edad y posteriormente en forma semanal.

- Consumo del alimento: Fue registrado semanalmente.

- Índice de conversión alimenticia (ICA): Se calculó semanalmente y en el acumulado, según la fórmula: Alimento consumido / Peso vivo.
- Mortalidad, eliminación y descartes: Se registró la mortalidad diaria. Se realizó, además, la necropsia para determinar la causa de muerte.

- Índice de eficiencia productivo europeo (IEPE): Se analizó al término del estudio, según la fórmula: (Viabilidad $\mathrm{x}$ Ganancia diaria de peso x 100) / ICA.

\section{Análisis de Datos}

La ganancia de peso, peso corporal, ICA e IEPE fueron analizados a través de un aná- 
lisis de varianza con contraste para T1 vs. T2, utilizando el programa SAS (Statistical Analisis System). Además, se utilizó la prueba de Shapiro-Wilk para determinar la distribucion normal de las variables. La mortalidad al final del estudio se evaluó mediante la prueba de Chi cuadrado para determinar asociación a los tratamientos.

\section{Resultados}

El peso corporal promedio, así como la ganancia de peso durante el periodo de crianza fue similar entre tratamientos (Cuadro 1); aunque se pudo observar que las aves del T2 mostraron una mayor velocidad de crecimiento, no significativa, a partir de la quinta semana del estudio. Tampoco se observó diferencias estadísticas en el consumo de alimentos ni en el IEPE (Cuadro 1).

La conversión alimenticia del grupo control fue mayor que en T1 y T2 (p<0.05) (Cuadro 1).

El mayor porcentaje de mortalidad fue observado en el T2 $(9.9 \%)$, asociado principalmente a un problema compatible con proceso tóxico (Cuadro 2); no obstante, la tasa de mortalidad no fue estadísticamente diferente entre tratamientos al final del estudio (Cuadro 1).

\section{Discusión}

El peso corporal y la ganancia de peso de las aves al final del estudio fue estadísticamente similar entre los tres tratamientos; resultados que coinciden con los de Vale et al. (2004); no obstante, Gamarra (2003) obtuvo una mayor ganancia de peso en pollos de engorde con la adición de ácidos orgánicos en el alimento. Estas diferencias entre estudios pudieron deberse al tipo y dosis de ácido orgánico empleado.
El consumo de alimento, si bien ligeramente menor en T2 en comparación con T1, fue estadísticamente similar entre tratamientos. Otros autores encontraron resultados similares, confirmando que el suplemento de ácidos orgánicos no afecta el consumo de alimento de las aves (Gamarra, 2003; Hernández et al., 2006; Adil et al., 2010). No obstante, la conversión alimenticia fue 2.6 y 5.2\% mejor entre el T2 frente a T1 y T3, respectivamente; habiendo significancia estadística entre T2 y T3 ( $<<0.05)$. Estas diferencias representan 181.4 g más de consumo de alimento por ave en T3 que en T2. Los resultados coinciden con los estudios de Adil et al. (2010), quienes también encontraron una mejor conversión alimenticia en pollos de engorde suplementados con ácidos orgánicos.

El T2 presentó un ligero, aunque no significativo, mejor peso vivo corporal y mejor conversión alimenticia; sin embargo, su IEPE fue afectada por la menor viabilidad $(90.1 \%)$ en comparación con los otros tratamientos, debido a los casos de mortalidad a consecuencia del cuadro compatible con proceso tóxico que afectó a este tratamiento. De no haberse presentado este problema, es posible que el T2 hubiese mostrado un mejor comportamiento productivo, especialmente en referencia al IEPE.

\section{Conclusiones}

- Los resultados del presente estudio demostraron que el efecto del uso de ácidos orgánicos como aditivos para mejorar el rendimiento productivo es similar al que se obtiene con el uso de promotores antibióticos como la Zinc Bacitracina.

- Los ácidos orgánicos pueden remplazar eficientemente a los promotores de crecimiento tipo antibióticos en la alimentación de las aves. 


\section{Literatura Citada}

1. Adil S, Banday T, Bhat GA, Mir MS, Rehman M. 2010. Effect of dietary supplementation of organic acids on performance, intestinal histomorphology, and serum biochemistry of broiler chicken. Vet Med Internat 2010: 479-485.

2. Al-Kassi AG, Mohssen MA. 2009. Comparative study between single organic acid effect and synergistic organic acid effect on broiler performance. Pakistan J Nutr 8: 896-899.

3. Alp M, Kocabagli N, Kahraman R, Bostan K. 1999. Effects of dietary supplementation with organic acids and zinc bacitracin on ileal microflora, $\mathrm{pH}$ and performance in broilers. Turk J Vet Anim Sci 23: 451-456.

4. [APA] Asociación Peruana de Avicultura. 2011. Asociación Peruana de Avicultura. [Internet], [20 agosto 2011]. Disponible en: http://www.apavic.com/html/ sections/acerca/acerca.asp

5. Carro MD, Ranilla MJ. 2002. Aditivos antibióticos promotores de crecimiento de los animales: situación actual y posibles alternativas. Sitio Argentino de Producción Animal. [Internet], [20 agosto 2011]. Disponible en: http://www.produccionanimal.com.ar/informa-cion_tecnica/invernada_promotores_crecimiento/00-invernada_promotores_del_crecimiento.htm

6. Dibner JJ, Buttin P. 2002. Use of organic acids as a model to study the impact of gut microflora on nutrition and metabolism. J Appl Poultry Res 11: 453463.

7. Dinabandhu J, Lichtenstein DL, Garner C. 2009. Salmonella control in feed: can organic acids application be an important part of the solution? In: $17^{\text {th }}$ Annual ASAIM SEA Feed Technology and Nutrition Workshop. Hue, Vietnam.

8. Gauthier R. 2002. La salud intestinal: clave de la productividad - El caso de los ácidos orgánicos. [Internet], [30 junio 2011]. Disponible en: http://
www.engormix.com/MA-avicultura/ nutricion/articulos/salud-intestinal-claveproductividad-t518/p0.htm

9. Gamarra R. 2003. Comparación de índices productivos en pollos de carne su plementados en la ración con sales de ácidos orgánicos versus Halquinol. Tesis de Médico Veterinario. Lima: Facultad de Medicina Veterinaria, Univ Nac Mayor de San Marcos. 32 p.

10. Hernández F, García V, Madrid J, Orengo J, Catalá P, Megías MD. 2006. Effect of formic acid on performance, digestibility, intestinal histomor-phology and plasma metabolite levels of broiler chickens. Br Poultry Sci 47: 50-56.

11. López A, Sánchez I, Cortes A, Órnelas M, Ávila E. 2009. Uso de dos promotores naturales como alternativas a antibióticos promotores en el comportamiento productivo del pollo de engorda. [Internet], [01 octubre 2010]. Disponible en: http://www.fmvz.unam.mx/fmvz/ centros/ceiepav/archivos/aneca_09/ Aaron_Ernesto_Lopez.pdf

12. [MINAG] Ministerio de Agricultura. 2011. Ministerio de Agricultura. [Internet], [25 julio 2011]. Disponible en: http://www.minag.gob.pe/pecuaria/ situacion-de-las-actividades-de-crianzay-produccion.html

13. Penz M. 1991. Hipótesis que justifican el uso de ácidos orgánicos en las dietas para aves y cerdos. Avicultura Prof 9(1): 46-51.

14. Peris S, Pérez L. 2001. Alternativas al uso de antibióticos como promotores de crecimiento en avicultura. En: XVII Congreso Latinoamericano de Avicultura. Guatemala.

15. Vale MM, Menten JFM, Morais SCD, Brainer MMA. 2004. Mixture of formic and propionic acid as additives in broiler feeds. Sci Agricola 61: 371-375.

16. Van Immerseel F, De Zutter L, Houf $K$, Pasmans $F$, Haesebrouck $F$, Ducatelle R. 2009. Strategies to control Salmonella in the broiler production chain. World Poultry Sci J 65: 367-392. 